\title{
Inhibitor of Ribosomal RNA Synthesis in Xenopus laevis Embryos. VII. Inhibition of 40S Pre-rRNA Synthesis in Xenopus Neurula Cells
}

\author{
Koichiro Shiokawa \\ Department of Biology, Faculty of Science, Kyushu University, Fukuoka 812, \\ Japan
}

\begin{abstract}
A fraction containing acid-soluble materials (PCA-extract) from Xenopus early blastulae preferentially inhibits the incorporation of $\left[{ }^{3} \mathrm{H}\right]$ uridine into $18 \mathrm{~S}$ and $28 \mathrm{~S}$ rRNA in Xenopus neurula cells. Pulse-laneling experiments revealed that whereas tubercidin, a known inhibitor of rRNA processing, produced a marked accumulation of the label in 40S pre-rRNA, Xenopus inhibitor suppressed labeling of the pre-rRNA. When tubercidin was added to cells whose activity for rRNA synthesis had been lowered by the Xenopus inhibitor, there was still an accumulation of label in the pre-rRNA. These results indicate that Xenopus inhibitor suppresses the synthesis of rRNA at transcription rather than at processing.
\end{abstract}

During the embryogenesis of Xenopus laevis, rRNA synthesis starts at about the mid-blastula stage $(12,13)$. A fraction containing an acid-soluble extract prepared from Xenopus early blastulae that had been partially purified with charcoal inhibits the synthesis of $18 \mathrm{~S}$ and $28 \mathrm{~S}$ rRNA preferentially when administered to isolated Xenopus neurula cells $(5,15,17)$. In Xenopus laevis, rRNA is transcribed as a $40 \mathrm{~S}$ pre-rRNA which is processed to form $18 \mathrm{~S}$ and $28 \mathrm{~S}$ mature $\mathrm{rRNA}(2,4,7,16)$. Therefore, as in the mechanism of inhibition of rRNA synthesis by the Xenopus inhibitor, two steps must be considered; transcription and processing. Our reported experiments show that the Xenopus inhibitor acts at the transcription level rather than in posttranscriptional processing.

Embryos of Xenopus laevis were dejellied and used at the early blastula (stage 7) (9) or neurula (stage 21-22) or tailbud (stage 24-25) stage. An inhibitor of rRNA synthesis was prepared from early blastulae by homogenizing the embryos with $0.3 \mathrm{~N} \mathrm{PCA}$ $(5,15)$. As the control, acid-soluble material was obtained from tailbud embryos. These materials were adsorbed on charcoal columns then eluted with ammonia-alcohol and used after repeated lyophilization $(5,15)$. They are here called the blastula and tailbud PCA-extracts.

To test the activity of the inhibitors, we isolated cells (14) obtained from 15 neurulae and labeled them with $\left[{ }^{3} \mathrm{H}\right]$ uridine $(25 \mathrm{Ci} /$ mmole) for $1 \mathrm{~h}$ in $1 \mathrm{ml}$ of medium in the presence or absence of PCA-extract equivalent to 20-60 embryos. As a reference substance, tubercidin, a known inhibitor of rRNA processing in Xenopus kidney cells (2), was administered at $0.5-1.0 \mu \mathrm{g} / \mathrm{ml}$ to normal or inhibited cultures.

Abbreviations used: PCA, perchloric acid; SDS, sodium dodecylsulfate. 
Labeled RNA was extracted from the frozen cells by phenol treatment in $0.1 \mathrm{M}$ sodium acetate, $\mathrm{pH} 5.0$, and $1 \mathrm{mg} / \mathrm{ml}$ bentonite- $0.5 \%$ SDS. The final aqueous phase was made $0.2 \mathrm{M}$ in $\mathrm{NaCl}$, then RNA was precipitated with 2.5 volumes of ethanol. The RNA was electrophoresed on $0.5 \%$ agarose $-2.0 \%$ polyacrylamide gels. Identification of the 40S rRNA precursor was made as described previously by Misumi et al. (7). Tubercidin was a gift from Dr. M. Saneyoshi, Hokkaido University.

When neurula cells were labeled for $1 \mathrm{~h}$, the 40S rRNA precursor and $28 \mathrm{~S}$ and $18 \mathrm{~S}$ mature rRNA appeared as distinct peaks on the electrophoretic profiles in addition to 4S RNA and RNA of heterogeneous size distribution (Fig. 1A). This profile is very similar to that of primary cultured Xenopus kidney cells pulse-labeled in the logarithmic phase of growth (7). When neurula cells were treated with the blastula PCA-extract, the accumulations of 40 S pre-rRNA, $28 \mathrm{~S}$ and $18 \mathrm{~S}$ mature rRNA were

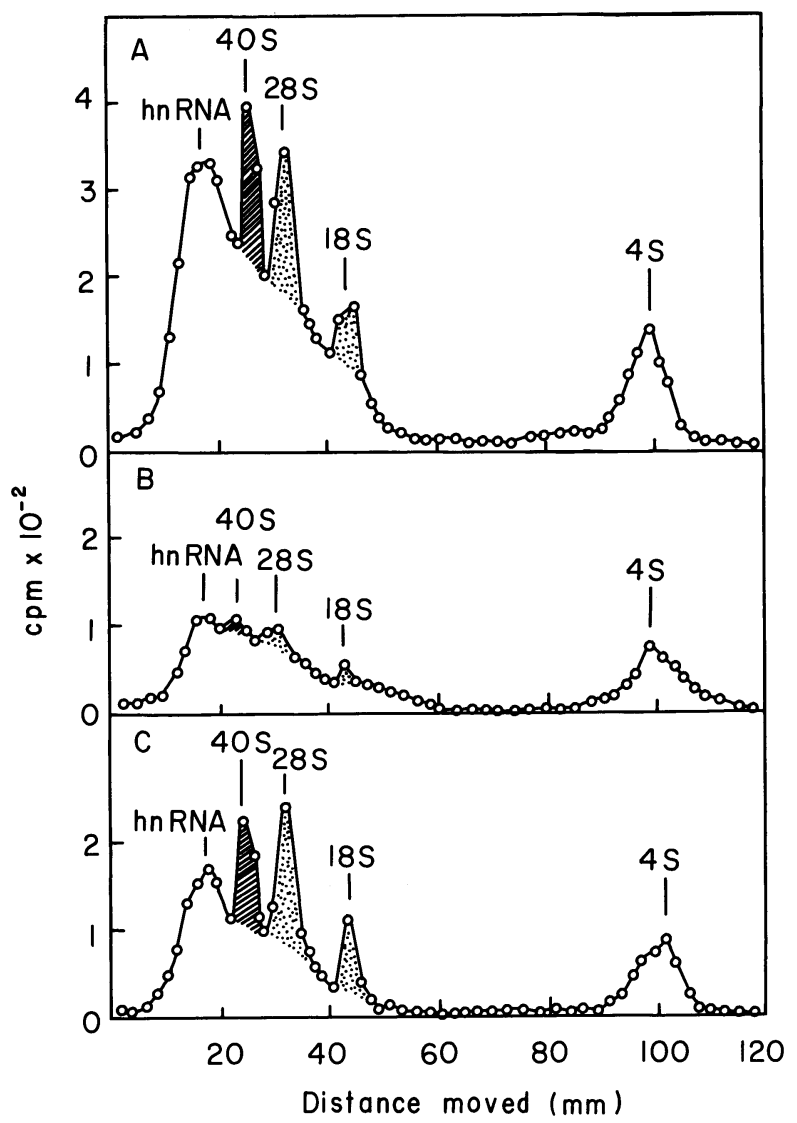

Fig. 1. Inhibition of the labeling of 40S pre-rRNA by PCA-extracts. Cells from 15 neurulae were cultured in $1 \mathrm{ml}$ of medium. The PCA-extract obtained from 20 embryos was added to the medium. Cells then were cultured for $2 \mathrm{~h}$, after which they were pulse-labeled in the same medium with $30 \mu \mathrm{Ci}$ of $\left[{ }^{3} \mathrm{H}\right]$ uridine for $1 \mathrm{~h}$. Shaded areas represent the 40S pre-rRNA, and dotted areas the $28 \mathrm{~S}$ and $18 \mathrm{~S}$ rRNA. A: Control, B: blastula PCA-extract and C: tailbud PCA-extract. 
greatly reduced, the respective inhibitions being about 90,81 and $87 \%$ (Fig. 1B). The labeling of heterogeneous non-ribosomal RNA also was inhibited; but, to a much less extent, about $60 \%$ for heterogeneous RNA and $50 \%$ for 4S RNA. When tailbud PCA-extract was tested, there was no preferential inhibition of rRNA labeling (Fig. $1 \mathrm{C})$.

The effect of tubercidin on the pattern of RNA labeling is shown in Fig. 2. Clearly the labeling of $18 \mathrm{~S}$ and $28 \mathrm{~S}$ rRNA was greatly inhibited, whereas that of $40 \mathrm{~S}$ prerRNA was concomitantly increased. A comparison of the results shown in Figs. 1 and 2 reveals that the effect of blastula PCA-extract differed markedly from that of tubercidin; the former inhibited the labeling of $40 \mathrm{~S}$ pre-rRNA, whereas the latter enhanced the accumulation of $40 \mathrm{~S}$ pre-rRNA.

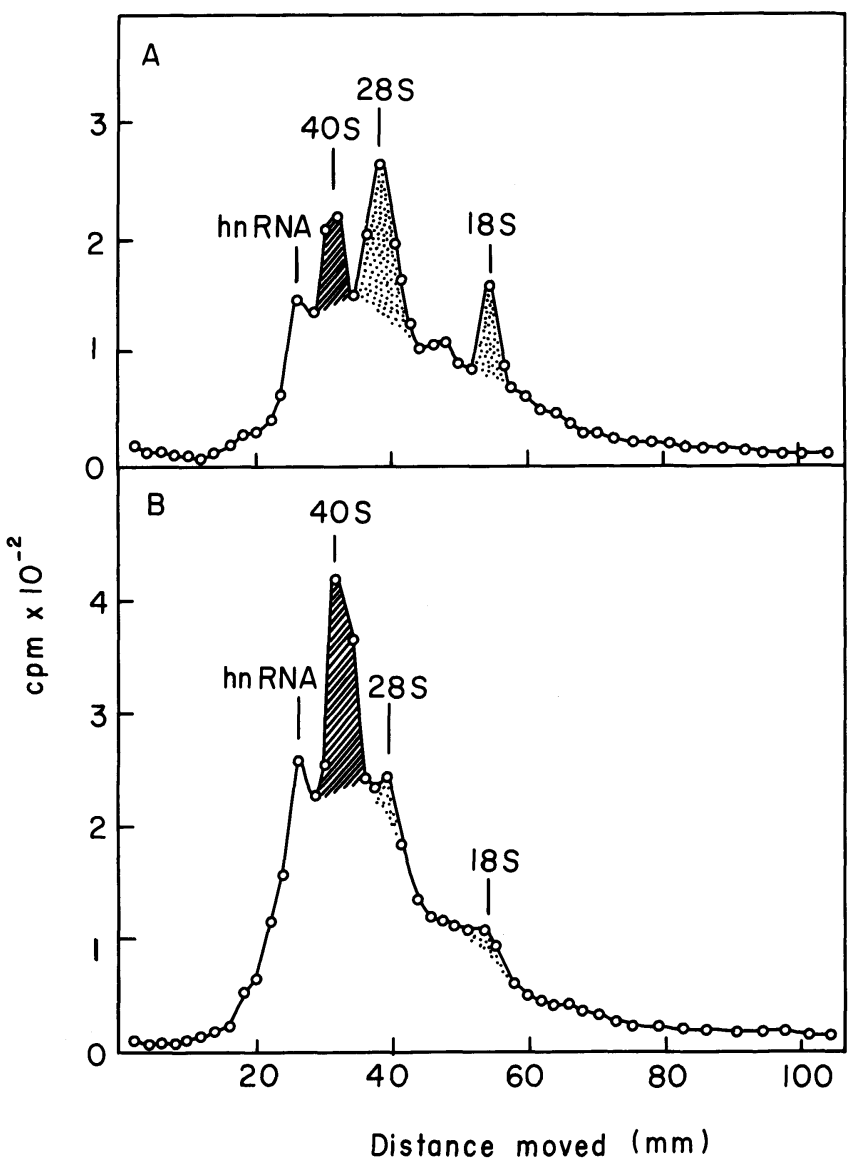

Fig. 2. Effects of tubercidin on the processing of $40 \mathrm{~S}$ pre-rRNA. Cells from 15 neurulae were treated with $0.5 \mu \mathrm{g} / \mathrm{ml}$ of tubercidin for $2.5 \mathrm{~h}$, then labeled as in Fig. 1 in the same medium for $1 \mathrm{~h}$ with $30 \mu \mathrm{Ci}$ of $\left[{ }^{3} \mathrm{H}\right]$ uridine. The $4 \mathrm{~S}$ RNA region is not included. $\mathrm{A}$ : control and $\mathrm{B}$ : treated with tubercidin. 
For Xenopus, 40S pre-rRNA is accepted to be the primary transcript $(2,4,7,8,16)$ although there have been some reports suggesting the existence of a larger precursor $(1,11)$. Thus, there is the implication that the PCA-extract suppresses formation of the primary transcript.

The processing of pre-rRNA clearly was not inhibited by the blastula PCA-extract because under the inhibition conditions used small amounts of $28 \mathrm{~S}$ and $18 \mathrm{~S}$ rRNA were formed (Fig. 1). The possibility must, however, still be considered that rRNA transcription was not inhibited although rapid degradation, or "wastage", took place. If $40 \mathrm{~S}$ pre-rRNA was formed normally but was degraded rapidly in the PCA-extracttreated neurula cells, there would be little accumulation of $40 \mathrm{~S}$ pre-rRNA in those

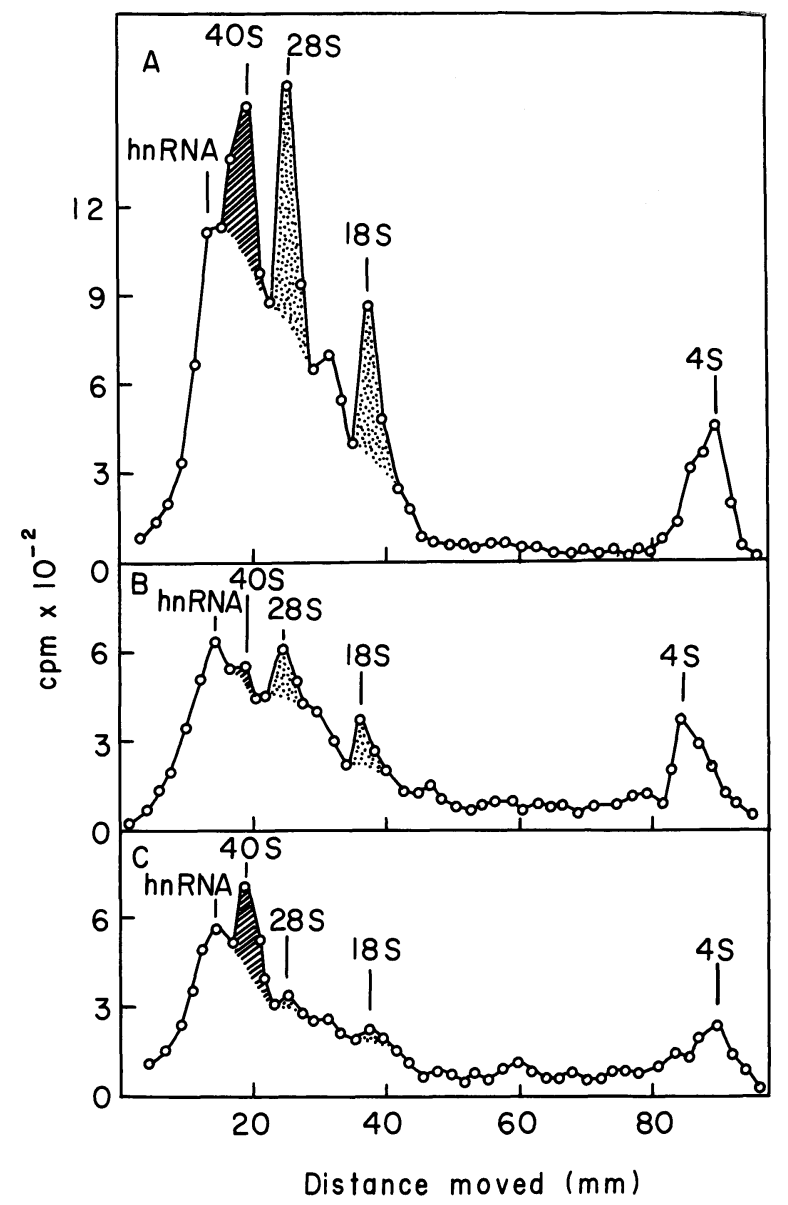

Fig. 3. Effects of tubercidin on the pattern of RNA labeling in cells treated with the blastula PCAextract. Cells from 15 neurulae were cultured for $2 \mathrm{~h}$ in the presence of blastula PCA-extract obtained from 60 embryos. Tubercidin then was added to the medium at $1 \mu \mathrm{g} / \mathrm{ml}$, and after $10 \mathrm{~min}$ of culture, the cells were labeled for $1 \mathrm{~h}$ in the same medium with $100 \mu \mathrm{Ci}$ of [ $\left.{ }^{3} \mathrm{H}\right]$ uridine. $\mathrm{A}$ : control, $\mathrm{B}$ : treated with the blastula PCA-extract and C: first treated with the PCA-extract then with tubercidin. 
cells when rRNA processing was inhibited by tubercidin. We therefore first treated neurula cells with the blastula PCA-extract for $2 \mathrm{~h}$ (as in Fig. 1B) then treated them with tubercidin (as in Fig. 2B).

As Fig. 3AB shows, the blastula PCA-extract again inhibited the labeling of $40 \mathrm{~S}$ pre-rRNA, $18 \mathrm{~S}$ and $28 \mathrm{~S}$ rRNA. When these inhibited cells were subsequently treated with tubercidin, formation of $18 \mathrm{~S}$ and $28 \mathrm{~S}$ rRNA was suppressed almost completely, the degree of suppression roughly corresponding to the amount of the label accumulated in the 40S pre-rRNA (Fig. 3C). Thus, in cells treated with the blastula PCA-extract, $40 \mathrm{~S}$ pre-rRNA was accumulated without being degraded.

Because the accumulation of $40 \mathrm{~S}$ pre-rRNA could be induced by tubercidin in cells treated with the blastula PCA-extract as it was in normal cells (Fig. 2B), the possibility of very rapid degradation of pre-rRNA in the blastula PCA-extract-treated cells is unlikely. We concluded that the blastula PCA-extract neither causes extensive degradation of the pre-rRNA nor inhibits its processing. Instead, the blastula PCAextract appears to inhibit rRNA synthesis at the transcription stage.

Reeder (10) reported that a PCA-extract prepared from unfertilized Xenopus eggs inhibited the transcription of rRNA but not that of 5S RNA in in vitro systems constructed with the purified 5S DNA templates and soluble fraction from Xenopus oocyte nuclei. We (3) also recently obtained results which show that crude Xenopus blastula extract inhibits the transcription of mouse rDNA in an in vitro system that was constructed by Muramatsu and his group (6). The results obtained from our present in vivo experiments are consistent with the results obtained in the in vitro experiments described above $(3,10)$, and are further evidence that Xenopus cleavage embryos contain a factor which negatively regulates rRNA synthesis $(5,15)$.

Acknowledgement. The research reported was supported, in part, by a Grant-in-Aid for Special Project Research from the Ministry of Education, Science and Culture of Japan.

\section{REFERENCES}

1. Caston, J.D. and P.H. Jones. Synthesis and processing of high molecular weight RNA by nuclei isolated from embryos of Rana pipiens. J. Mol. Biol. 69, 19-38, 1972

2. Hagenbüchle, O., U. Schibler and T. Wyler. Intermolecular renaturation of hairpin loops to stable and specific aggregates of 28-S rRNA and precursor rRNAs from Xenopus laevis. Eur. J. Biochem. 60, 73-82, 1975

3. Kobayashi, H., K. Nomura, K. Shiokawa and K. Yamana. Transcriptional inhibition of Xenopus embryonic fraction in a mouse transcription system in vitro. Develop. Growth Differ. 25, 424, 1983

4. Landesman, R. and P.R. Gross. Pattern of macromolecule synthesis during development of Xenopus laevis II. Identification of the 40S precursor to ribosomal RNA. Dev. Biol. 19, 244-260, 1969

5. Laskey, R.A., J.C. Gerhart and J.S. Knowland. Inhibition of ribosomal RNA synthesis in neurula cells by extracts from blastulae of Xenopus laevis. Dev. Biol. 33, 241-248, 1973

6. Mishima, Y., O. Yамаmoto, R. Kominami and M. Muramatsu. In vitro transcription of a cloned mouse ribosomal RNA gene. Nuc. Acids Res. 9, 6773-6785, 1981

7. Misumi, Y., Y. Nishio, K. Shiokawa and K. Yamana. RNA metabolism in primary cultures of Xenopus laevis kidney cells III. Processing of rRNA precursor in growing and resting cells. Exptl. Cell Res. 114, 239-245, 1978

8. Moss, T. A transcriptional function for the repetitive ribosomal spacer in Xenopus laevis. Nature 302, 223-228, 1983 
9. Nieuwkoop, P.D. and J. FAber. Normal Table of Xenopus Laevis (Daudin). North-Holland, Amsterdam, 1956

10. REEDER, R.H. An inhibitor of ribosomal RNA synthesis in unfertilized eggs. Carnegie Inst. Year. Book 77, 114-116, 1978

11. Rungger, D., H. Achermann and M. Crippa. Transcription of spacer sequences in genes coding for ribosomal RNA in Xenopus cells. Proc. Natl. Acad. Sci. U.S.A. 76, 3957-3961, 1979

12. Shiokawa, K., Y. Misumi and K. Yamana. Demonstration of rRNA synthesis in pre-gastrular embryos of Xenopus laevis. Develop. Growth Differ. 23, 579-587, 1981

13. Shiokawa, K., K. Tashiro, Y. Misumi and K. Yamana. Non-coordinate synthesis of RNA's in pre-gastrular embryos of Xenopus laevis. Develop. Growth Differ. 23, 589-597, 1981

14. Shiokawa, K. and K. Yamana. Pattern of RNA synthesis in isolated cells of Xenopus laevis embryos. Dev. Biol. 16, 368-388, 1967

15. Shiokawa, K. and K. Yamana. Inhibitor of ribosomal RNA synthesis in Xenopus laevis embryos IV. The release of inhibitor from cultured cells. Dev. Biol. 47, 303-309, 1975

16. Wellauer, P.K. and I.B. Dawid. Secondary structure maps of ribosomal RNA and DNA: I. Processing of Xenopus laevis ribosomal RNA and structure of single-stranded ribosomal DNA. J. Mol. Biol. 89, 379-395, 1974

17. Yamana, K. and K. Shiokawa. Inhibitor of ribosomal RNA synthesis in Xenopus laevis embryos V. Inability of the inhibitor to repress 5S RNA synthesis. Dev. Biol. 47, 461-463, 1975

(Received for publication, February 9, 1984) 